\title{
An Evolutionary Decade
}

\author{
Linda V. Knight, Editor-in-Chief \\ DePaul University, Chicago, IL, USA
}

\author{
editor@jite.org
}

\section{Our Tenth Anniversary}

As we celebrate the tenth anniversary of the Journal of Information Technology Education, it is fitting to pause and reflect on the journal's growth over the years. Eli Cohen began the journal in 2002 , with an original group of six editors. When I was promoted to Editor-in-Chief in January 2005 , that original group had grown to nine editors from six countries on four continents. Now, as we celebrate our tenth anniversary, we have more than 20 editors from a dozen countries on 5 continents. The number of editors was expanded to keep pace with the rapid growth in the number of papers submitted. Much of that growth is due to the journal's adherence to the vision and values of the Informing Science Institute.

\section{Colleagues Mentoring Colleagues}

A guiding principle of the Informing Science Institute is the ideal of colleagues mentoring one another. Our goal is always to publish high quality papers and to ensure that each paper is developed to its maximum possible level. JITE's International Board of Reviewers, with over 200 reviewers from 47 countries, allows us to assign six reviewers to each paper from around the globe, thus providing a particularly broad perspective on each manuscript. Our editors, themselves established researchers, act as collegial mentors for our authors, providing them with the guidance needed to maximize the quality and impact of their work. We take this mentoring approach even with papers that we do not accept for publication, thus ensuring that every author who submits to JITE receives a thorough and constructive response.

\section{Our Evolving Focus}

Over the years, we have seen technology play an ever-increasing role in education. When our journal first began, articles focused on teaching of IT subject matter at the university level. However over the years, we have expanded that focus to encompass the entire intersection of Information Technology and education. Thus, we now publish articles on the use of IT for education in all subject areas and at all grade levels, in addition to articles on the teaching and learning of IT subjects. This broader focus has enabled us to provide educators with access to the best ITrelated research. It also is responsible in part for our vastly expanded readership. In the month of October 2011 alone, our website had over 32,000 visitors from 25,000 unique IP addresses in 119 different countries.

\section{JITE Innovations in Practice - Now a Separate Publication}

First and foremost, our readers want sound research, but in addition, they also want cutting edge ideas that they can implement within their courses. Out of this interest was born our Innovations in Practice section. JITE: Innovations in Practice began in 2008 with five articles. This year, it is being published as a separate volume for the first time. This year's articles cover such topics as educational applications of social networking, web-based collaborative writing, virtual universities, a graduate course in text analytics, and much more. JITE Innovations is a collection of the latest and most unique teaching advancements. In contrast to papers that primarily build theory, 
JITE Innovations focuses on quality manuscripts that present, in an academically sound manner, new and enticing teaching ideas involving information technology. Often, the teaching approach is so new that the substantial supportive data normally required for full research papers could not be gathered. However, to delay publication would deprive the academic community of knowledge that is at the forefront of educational thought.

\section{Opportunities for Authors}

We are particularly interested in quality research on topics such as (but not limited to) the use of technology in the classroom, online learning, teaching of IT subject matter, and applying IT to the teaching of any subject. All manuscripts are submitted and reviewed electronically. Reviewers are selected from among our over 200-member international panel based on their familiarity with the subject matter of the manuscript. With more than 20 editors from a dozen countries on five continents, we are truly an international journal. Feedback to authors is rapid and collegial. Our published authors have the advantage of both a quality print publication and the widespread readership that comes from publishing all articles online within a few weeks of acceptance. This approach ensures that JITE: Research articles are read and cited by the largest possible potential audience.

\section{Opportunities for Reviewers}

If you are willing to turn around reviews rapidly electronically and wish to join our International Board of Reviewers, email a current C.V. or resume to editor@jite.org. We welcome all who have a record of publishing in peer-reviewed journals to consider joining the JITE family.

\section{Recognition}

As our tenth annual volume goes to press, I wish to publically thank all of our readers, as well as those whose hard work has made the journal's success a reality: Eli Cohen, our Managing Editor, whose vision was the spark that ignited the entire Informing Science Institute family of journals and whose tireless energy keeps the ISI passion alive; Betty Boyd, our Publisher who has filled in recently as my editorial assistant, and whose ceaseless efforts and determined attention to detail have been critical to the quality of the journal; our authors, published and unpublished, who have supported our journal by trusting us with the fruits of their labors; members of our International Board of Reviewers, whose thoughtful and rapid reviews provide the basis for the quality and timeliness of our journal; and our Editors, whose collegial work with our authors is the ultimate key to the journal's excellence. As we begin our 11th year of publication, we are indebted to all of you for the journal's success. 